Thorax (1974), 29, 463.

\title{
The heart and pulmonary vasculature of the llama (Lama glama)
}

\author{
D. H E A T H, P. S M I T H, D. W I L L I A M S, P H A R R I , \\ J.A R I A S-S T E L L A, a nd H. K R Ü G R \\ The Department of Pathology, University of Liverpool, Cardiothoracic Institute, University of \\ London, and the High Altitude Research Unit, Cayetano Heredia Medical School, Lima, Peru
}

\begin{abstract}
Heath, D., Smith, P., Williams, D., Harris, P., Arias-Stella, J., and Krïger; H. (1974). Thorax, 29, 463-471. The heart and pulmonary vasculature of the llama (Lama glama). A qualitative and quantitative histological study was made of the pulmonary trunk and muscular pulmonary arteries of a male and a pregnant female llama born and living at an altitude of $4,720 \mathrm{~m}$ above sea-level in the Peruvian Andes. A similar study was made on the fetal llama. The individual cardiac chambers of the two adults were weighed. Our results show that in the adult llama there is no hypertrophy of the right ventricle or of the media of the pulmonary trunk or small pulmonary arteries. This appears to be of evolutionary significance in respect of survival at high altitude and suggests that the llama does not have a sustained significant pulmonary hypertension. The pulmonary arteries of the fetal llama are thick-walled and we associate this with the physiological pulmonary hypertension of fetal life.
\end{abstract}

There is now much convincing evidence that in most species the pulmonary arterial tree responds to a hypoxic stimulus by constriction. This leads to an increase in medial thickness of the terminal portions of the pulmonary arterial tree, an elevated pulmonary vascular resistance, and consequent right ventricular hypertrophy. Thus Abraham, Kay, Cole, and Pincock (1971) subjected rats to a simulated high altitude of $5,500 \mathrm{~m}$ in a decompression chamber and found that during the course of 33 days they showed a progressive rise in right ventricular mean pressure and weight and the development of muscularized pulmonary arterioles and increased medial thickness of muscular pulmonary arteries. Arias-Stella and Saldaña (1963) showed that the same phenomenon occurs naturally in men exposed to the chronic hypoxia associated with mountain dwelling. They found that in the Quechua Indians living permanently in Andean towns above altitudes of $3,440 \mathrm{~m}$ there is a greater amount of muscle in the more distal segments of the pulmonary arterial tree. In some species the effect of hypoxia on the pulmonary circulation is severe. Thus cattle living at high altitude in the region of Salt Lake City may develop 'brisket disease' in which an increased pulmonary vascular resistance is produced by the hypoxia and leads on to right ventricular hypertrophy and congestive cardiac failure (Hecht et al., 1959); the increased pulmonary vascular resistance is associated with medial hypertrophy of the small pulmonary arteries (Alexander, 1962). In a previous study we found that the pulmonary arteries of cats and dogs living at high altitude are thick compared to representatives of the same species living at sea level (Heath, Castillo, Arias-Stella, and Harris, 1969). In the same study we found that the pulmonary arteries of a llama were much thinner and suggested that this might be of evolutionary significance in respect of survival at high altitude. This view was subsequently challenged by Banchero, Grover, and Will (1971) who illustrated a thickwalled muscular pulmonary artery and a muscularized pulmonary arteriole in a llama taken to high altitude in the Colorado Rockies. On a recent expedition to the Peruvian Andes in 1973 we were again impressed by the remarkable tolerance of llamas to life at high altitude and decided to examine the pulmonary vasculature of further members of this species to check our previous findings. 


\section{METHOD AND MATERIALS}

We studied a male and a female llama. Both were 2 years old. They had been born and lived all their lives on an estancia at Rancas which is situated at an altitude of $4,720 \mathrm{~m}$ above sea level (Fig. 1). The female llama was pregnant, and this offered an opportunity for the study of the lungs and pulmonary vasculature of the fetal llama.

The animals were killed and the heart and lungs were removed and taken to the High Altitude Research Station at Cerro de Pasco, a few kilometres distant. There the right lungs from all three llamas were distended with $10 \%$ formol saline until the pleural surfaces were smooth. The lungs were cut into slices $2 \mathrm{~cm}$ thick after fixation and these were transported to Liverpool for histological study. Blocks of lungs were resected and paraffin sections $5 \mu \mathrm{m}$ thick were cut and stained with haematoxylin and eosin, and by the Miller method to demonstrate elastic tissue with a Van Gieson counterstain to demonstrate muscle and collagen. A histological investigation of the various classes of pulmonary blood vessel was carried out. A quantitative study of the medial thickness of the 'muscular pulmonary arteries' was made. Measurements were made of the diameter and average thickness of the media of arteries up to $250 \mu \mathrm{m}$ in diameter in the adult llamas and up to $125 \mu \mathrm{m}$ in diameter in the fetal llama. Only vessels that were virtually circular in transverse diameter were measured; this method of selection decreased the number of arteries included in each study but avoided error in the measurement of the vessel diameter. The diameter was taken as the mean of two measurements, at rightangles to each other, of the distance between diametrically opposite points on the external elastic lamina. The medial thickness was estimated as the mean of four measurements taken at points approximately equally spaced around the vessel wall. From these data the thickness of the media was expressed as a percentage of the external diameter.

In both cases the heart was dissected free of fat. It was opened and the circumferences of the cardiac valves were measured. The individual cardiac chambers were then separated and weighed according to $\stackrel{\mathbb{D}}{\AA}$ the method of Fulton, Hutchinson, and Jones (1952). \& The weight of the right ventricle was expressed as an inverse ratio of left ventricular weight.

Circumferential rings of pulmonary trunk and aorta were resected $1 \mathrm{~cm}$ distal to the respective $\mathscr{\sigma}$ valves. The tissue was embedded, and paraffin sections $5 \mu \mathrm{m}$ in thickness were stained by the Miller method for elastic tissue to delineate the media. Ten measure- No ments of the medial thickness of both arteries were $\rightarrow$ made and a mean medial thickness was then calculated for both. A direct ratio of the medial thickness $\mathcal{E}$ of the pulmonary trunk to that of the aorta (PT/A) 은 was then calculated for both animals.

\section{RESULTS}

The circumferences of the cardiac valves and the weights of the chambers of the heart in the adult llamas are shown in Table I. The medial thickness of the pulmonary trunk and aorta and the PT/A ratio in these two animals are shown in Table II. The percentage medial thicknesses of muscular pulmonary arteries in the three llamas are shown in Table III.

\section{STRUCTURE OF THE DIFFERENT CLASSES OF PULMONARY BLOOD VESSEL}

Pulmonary trunk The pulmonary trunk of the llama is very muscular compared to that of man. In the outer media and extending into the

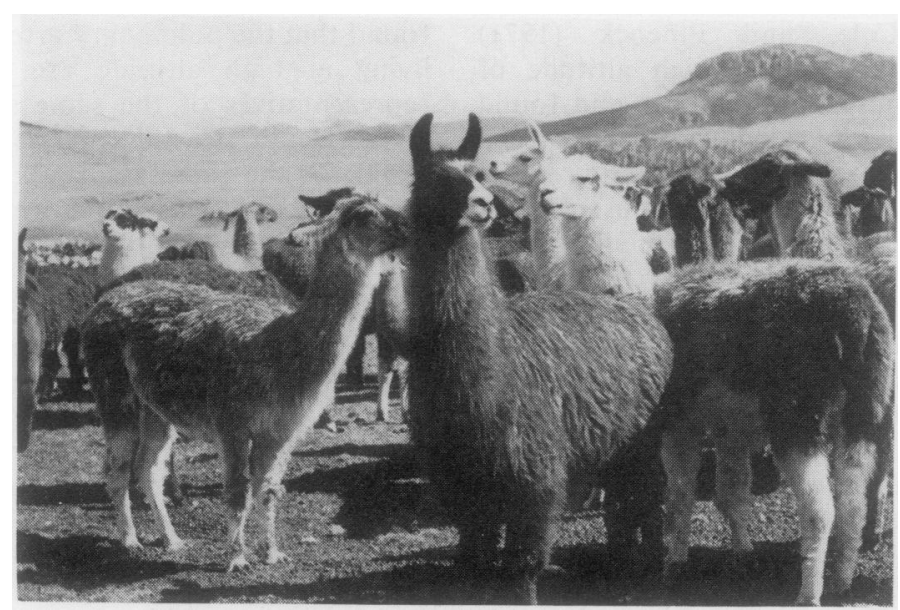

FIg. 1. Llamas at Rancas in the Peruvian Andes at an altitude of $4,720 \mathrm{~m}$ above sea level. 
T A B L E I

WEIGHTS (g) OF HEART AND INDIVIDUAL CARDIAC CHAMBERS AND CIRCUMFERENCES (mm) OF VALVES IN ADULT LLAMAS

\begin{tabular}{|c|c|c|c|c|c|}
\hline Chamber & Female & Male & Valve & Female & Male \\
\hline Right ventricle & $60 \cdot 5$ & $52 \cdot 5$ & Pulmonary & 50 & 52 \\
\hline $\begin{array}{l}\text { Left ventricle } \\
\text { and inter- } \\
\text { ventricular } \\
\text { septum }\end{array}$ & $206 \cdot 9$ & $156 \cdot 0$ & Tricuspid & 98 & 100 \\
\hline Right atrium & $15 \cdot 4$ & $13 \cdot 3$ & Aortic & 55 & 55 \\
\hline Left atrium & $15 \cdot 4$ & $13 \cdot 4$ & Mitral & 84 & 85 \\
\hline $\mathbf{L V}+\mathbf{S}$ & $3 \cdot 5$ & $3 \cdot 0$ & & & \\
\hline RV & & & & & \\
\hline Total weight & $298 \cdot 2$ & $235 \cdot 2$ & & & \\
\hline
\end{tabular}

T A B L E I I

MEAN MEDIAL THICKNESS $(\mu \mathrm{m})$ OF AORTA AND PULMONARY TRUNK AND PT/A RATIO IN TWO ADULT LLAMAS

\begin{tabular}{l|c|c}
\hline & Female & Male \\
\hline Aorta & 2,510 & 2,230 \\
Pulmonary trunk & 1,620 & 1,330 \\
PT/A & 0.64 & 0.57 \\
\hline
\end{tabular}

T A B L E I I I

PERCENTAGE MEDIAL THICKNESS OF MUSCULAR PULMONARY ARTERIES IN THREE LLAMAS

\begin{tabular}{|c|c|c|c|c|}
\hline \multirow[t]{2}{*}{ Llama } & \multirow{2}{*}{$\begin{array}{c}\text { No. of } \\
\text { Vessels } \\
\text { Examined }\end{array}$} & \multirow{2}{*}{$\begin{array}{c}\text { Range of } \\
\text { Diameters } \\
(\mu \mathrm{m})\end{array}$} & \multicolumn{2}{|c|}{$\begin{array}{c}\text { Percentage Medial } \\
\text { Thickness }\end{array}$} \\
\hline & & & Range & Mean $^{1}$ \\
\hline Female & 67 & $35-198$ & $0.57-10.26$ & $3 \cdot 8$ \\
\hline Male & 101 & $28-233$ & $1.82-10.58$ & 4.9 \\
\hline Fetus & 94 & 26-111 & $8.91-28.57$ & 20.0 \\
\hline
\end{tabular}

${ }^{1}$ Expressed to first place of decimals.

adventitia are thick bands and nodules of smooth muscle (Fig. 2). The media also contains much elastic tissue. In the outer half of the media the elastic fibrils are thick, long, and wavy and appear to be connected by much thinner fibrils. Between the elastic fibrils are bands of smooth muscle arranged circumferentially in the main and progressing in size to the muscular nodules at the junction of media and adventitia described above. In the inner half of the media smooth muscle is less prominent, although individual fibres are seen (Fig. 3). Collagen is more in evidence here. In this inner part of the wall of the pulmonary trunk the elastic fibrils are arranged both circumferentially and longitudinally, and as a result even

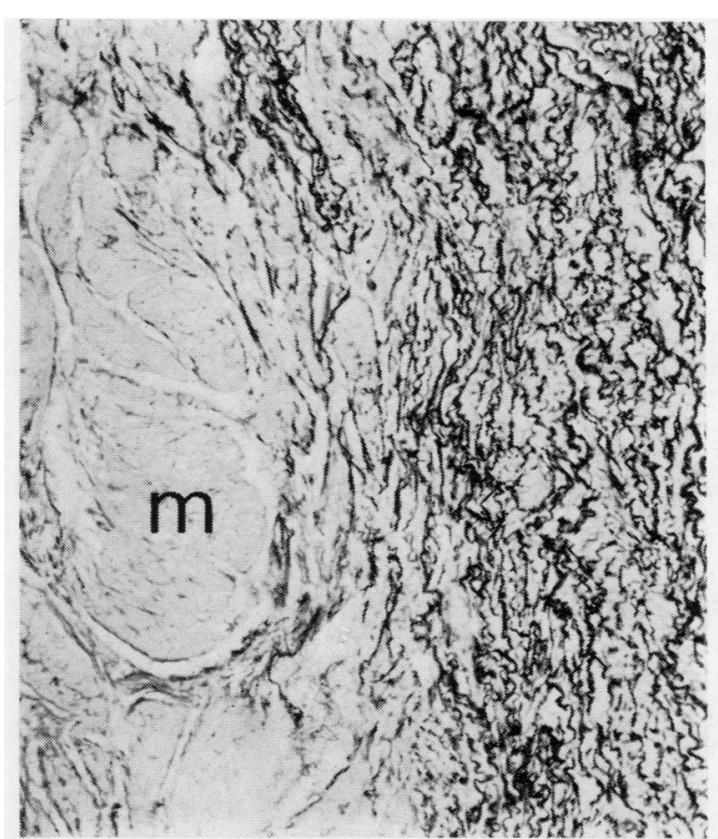

FIG. 2. Part of transverse section of pulmonary trunk from an adult llama. The outer third of the media is shown, the adventitia lying to the left. Thick bands and nodules of smooth muscle $(m)$ are seen to the left. The elastic fibrils of the outer media, seen to the right, are thick, long, and crenated. (Elastic van Gieson, $\times 105$.)

at low magnification this inner zone can be delineated easily. There is a thick internal elastic lamina and immediately beneath this is a very narrow zone of tightly packed elastic fibrils arranged longitudinally (Fig. 4).

Elastic pulmonary arteries The branches of the main extrapulmonary arteries have much elastic tissue within their media and are consequently termed 'elastic pulmonary arteries'. Even the smallest representatives of this class of vessel seen way out in the periphery of the lung have up to eight thick, well-defined elastic fibrils spaced throughout the media and running circumferentially. Finer wispy elastic fibrils are seen between these large fibrils. The elastic tissue tends to be thicker in the inner media. There is much circularly arranged smooth muscle between the elastic fibrils. Smaller amounts of fibrous tissue are present. There is no intimal fibrosis. The adventitia of collagen contains elastic fibrils.

Muscular pulmonary arteries (Figs 5 and 6) The elastic pulmonary arteries give rise to muscular pulmonary arteries. As the elastic arteries get 


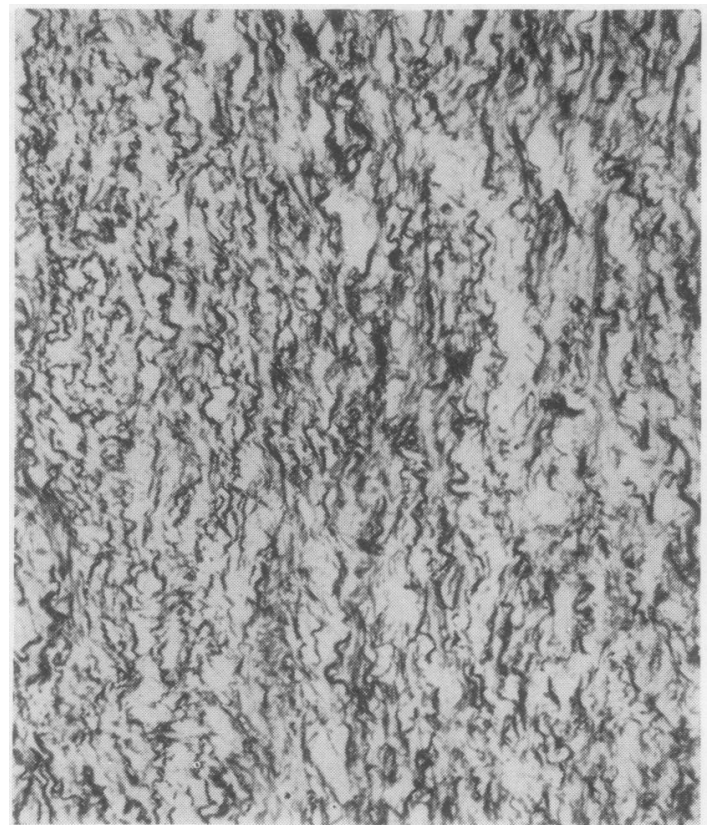

FIG. 3. Part of the same transverse section. In the middle third of the media shown in the figure the muscle is in the form of individual fibres between the elastic laminae. (Elastic van Gieson, $\times 105$.)

smaller the number of elastic fibrils within the media becomes fewer, and finally branches arise which have the structure of a 'muscular pulmonary artery'. In spite of this designation, taken from the classification of Brenner (1935) for comparable vessels in the human lung, the most characteristic feature of the 'muscular pulmonary artery' in the llama is that it is very thin-walled. The media consists of a thin layer of circularly orientated smooth muscle sandwiched between internal and external elastic laminae. Small wisps of elastic tissue are also seen within the media. There is no intimal fibrosis. The adventitia of collagen contains an admixture of thin elastic fibrils.

Pulmonary arterioles (Fig. 7) These arise as side branches and terminations of the thin-walled muscular pulmonary arteries, and their walls consist of a single elastic lamina. The lung of the adult llama is not characterized by large numbers of thick-walled, muscular arterioles like those found in the systemic circulation of mammals.

Pulmonary venules (Fig. 8) The venules resemble the arterioles in structure with walls consisting of a single elastic lamina. They arise by confluence of pulmonary capillaries.
Sma!l pulmonary veins (Fig. 9) The pulmonary $\overrightarrow{\vec{B}}$ venules drain into small pulmonary veins which have a thick, crenated elastic lamina external to $\frac{\mathrm{C}}{\mathrm{O}}$ a thin muscular media which is ill-defined and $\overline{\overline{0}}$ devoid of a distinct internal elastic lamina. The $\underset{\mathbb{D}}{ }$ elastic fibrils within the media are thin and short $\varrho$ and orientated circumferentially. The small veins कs do not show intimal fibrosis. There is a fibrous $\overrightarrow{0}$ adventitia.

Large pulmonary veins There is a well-defined $\vec{\omega}$ media in this class of vessel. The elastic fibrils of $\vec{x}$ the media are thinner than in the elastic pul- i monary artery. They are well-defined and run circumferentially. Individual smooth muscle fibres are present between the elastic fibrils. There is $\mathrm{\omega}^{\circ}$ more collagen in the media than in that of the 을 elastic pulmonary arteries, and the tissue com- ponents of the media are less compactly arranged. $\subsetneq$ There is no intimal fibrosis. The fibrous adventitia contains wispy elastic fibrils.

FETAL LLAMA

Elastic pulmonary arteries (Fig. 10) These have a thick media in which are situated about 10-15

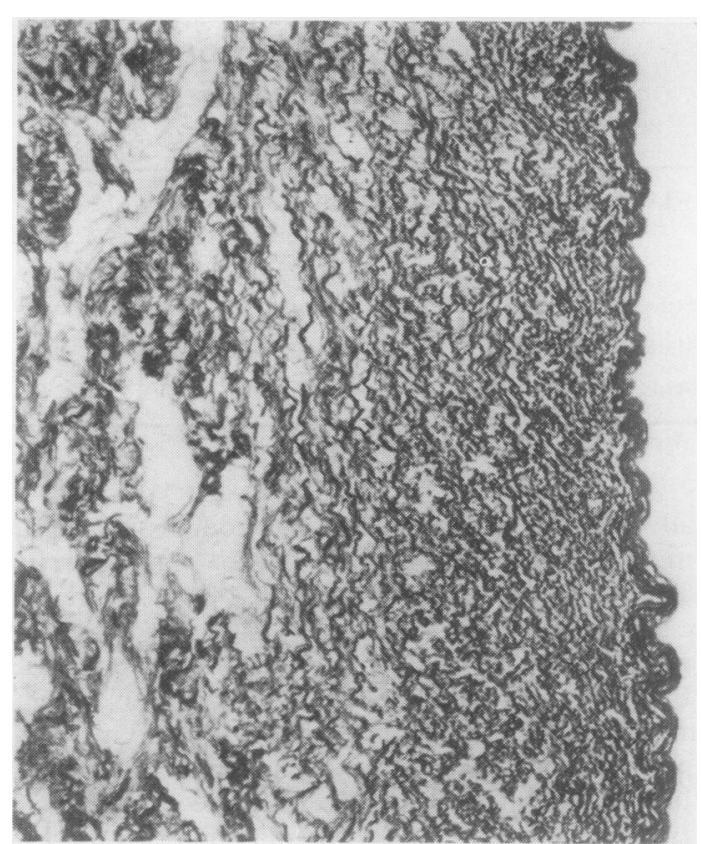

FIG. 4. Part of the same transverse section. The inner third of the media is shown, the intima lying $\overrightarrow{\mathbb{D}}$ to the right. There is a thick internal elastic lamina $\stackrel{\rho}{+}$ and beneath this is a narrow zone of tightly packed $\unrhd$ elastic fibrils, many of which are orientated longitudinally. (Elastic van Gieson, $\times 105$.) 


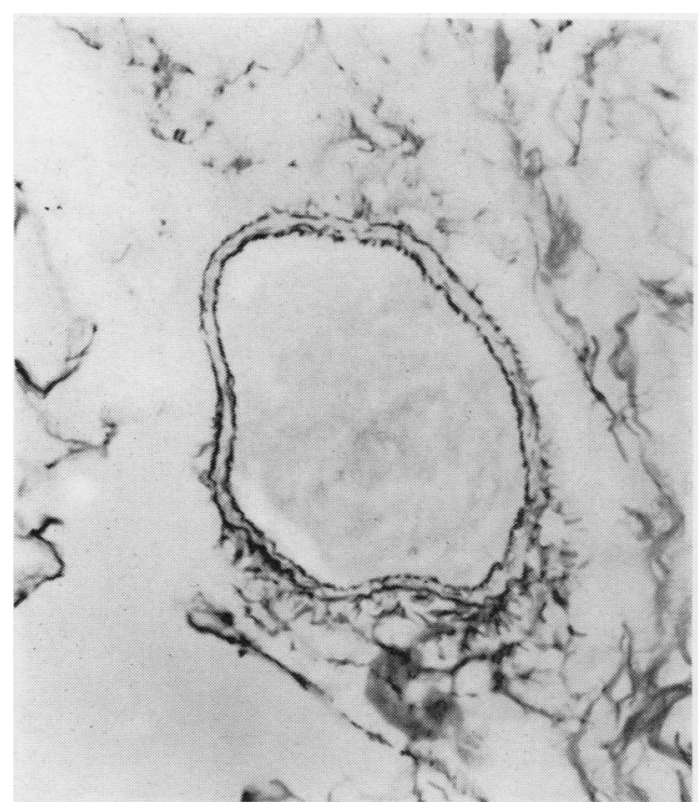

FIG. 5. Transverse section of a muscular pulmonary artery from an adult llama showing the thin media of circularly orientated smooth muscle bounded by internal and external elastic laminae. Contrast with the thick-walled pulmonary artery of the fetal llama shown in Fig. 11. (Elastic van Gieson, $\times 345$.)

concentric elastic laminae which are thick and well defined. Wispy elastic fibrils are found between the main laminae. There is no intimal fibrosis. A thick fibrous adventitia contains a few thin elastic fibrils.

Muscular pulmonary arteries (Fig. 11) In striking contrast to the state of affairs in the adult llama, the muscular pulmonary arteries of the fetus are very thick-walled and composed of circularly orientated smooth muscle bounded by internal and external elastic laminae. The endothelial cells are prominent but there is no intimal fibrosis.

Small pulmonary veins These are composed of a thick elastic lamina lined on its inner aspect by a few smooth muscle fibres and a surrounding fibrous adventitia.

Large pulmonary veins In this class of vessel the media is thinner than in the elastic pulmonary arteries. The elastic laminae are thin and individual muscle fibres are seen between them together with considerable amounts of collagen. There is no intimal fibrosis.

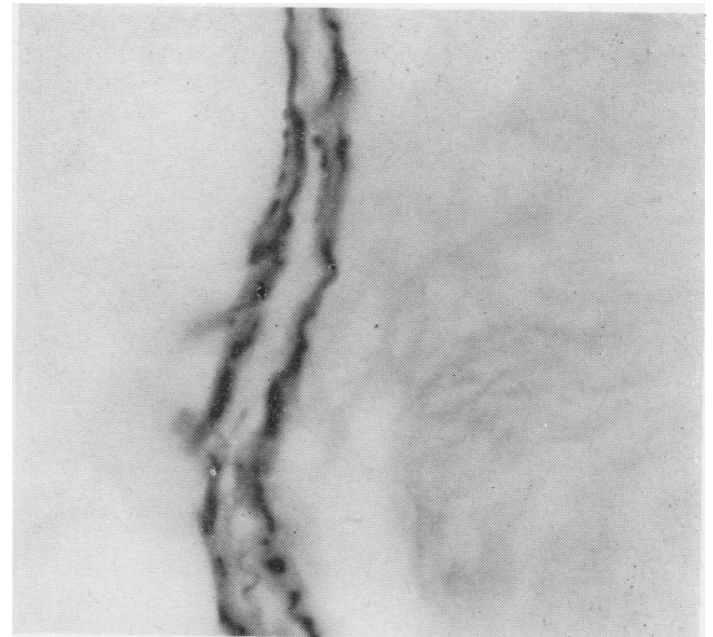

FIG. 6. Part of the preceding figure at higher magnification to show the thin media and the elastic laminae. (Elastic van Gieson, $\times 1,270$.)

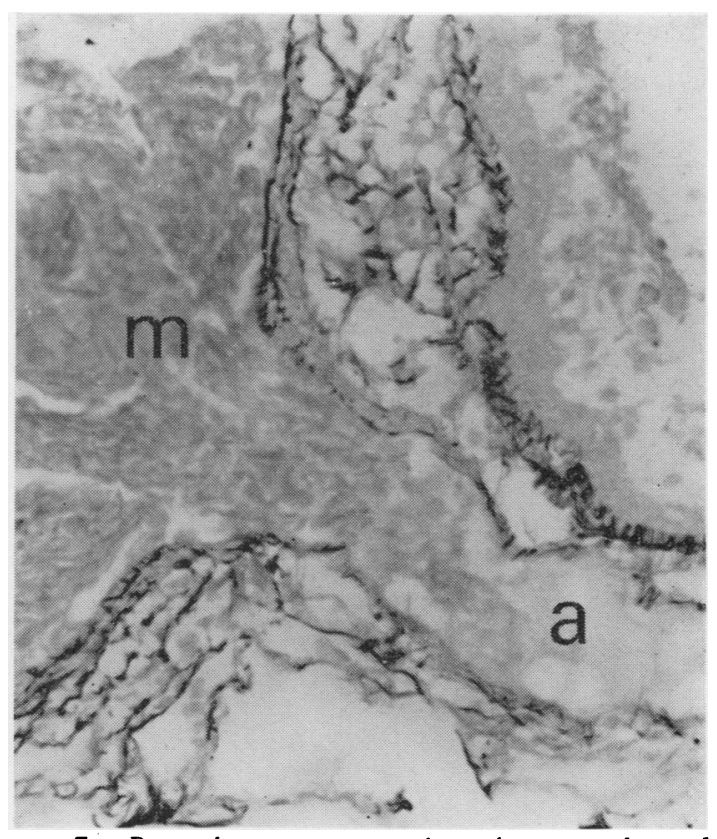

FIG. 7. Part of transverse section of a muscular pulmonary artery $(m)$ from an adult llama showing the origin of an arteriole (a). The media of the artery is very thin and consists of muscle sandwiched between internal and external elastic laminae. The arteriole does not have a muscular media. (Elastic van Gieson, $\times 345$.) 


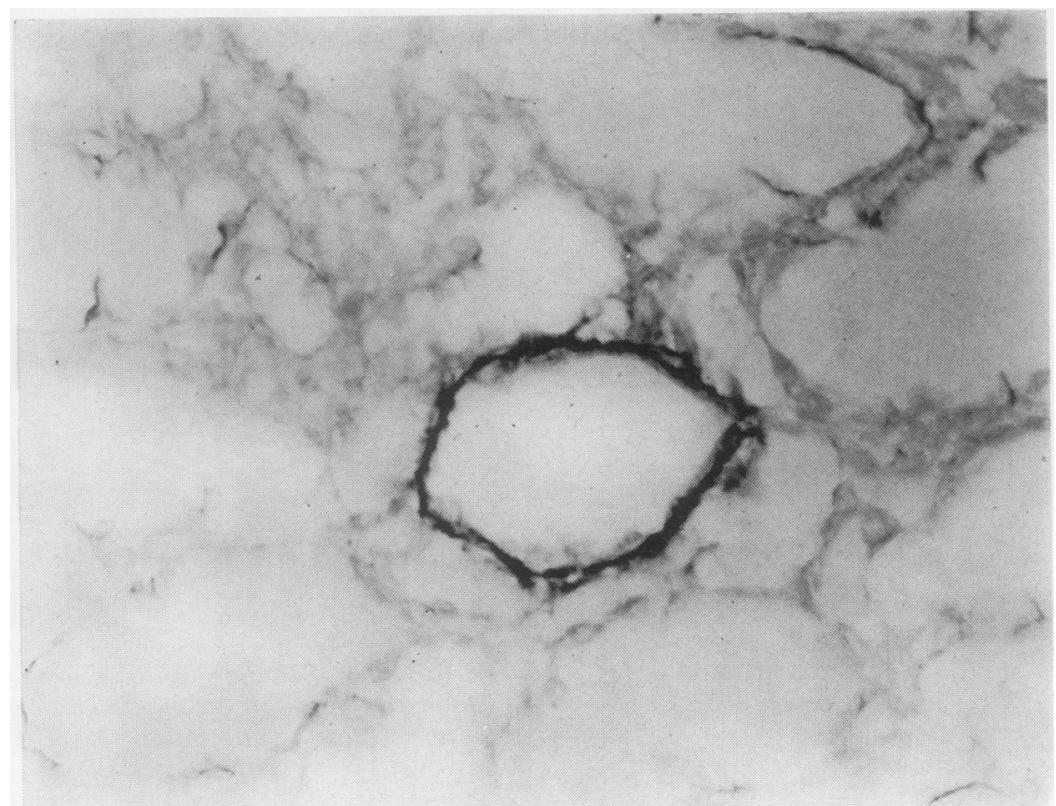

FIG. 8. Transverse section of a pulmonary venule from the fetal llama. It consists of a single elastic lamina. (Elastic van Gieson, $\times 600$.)

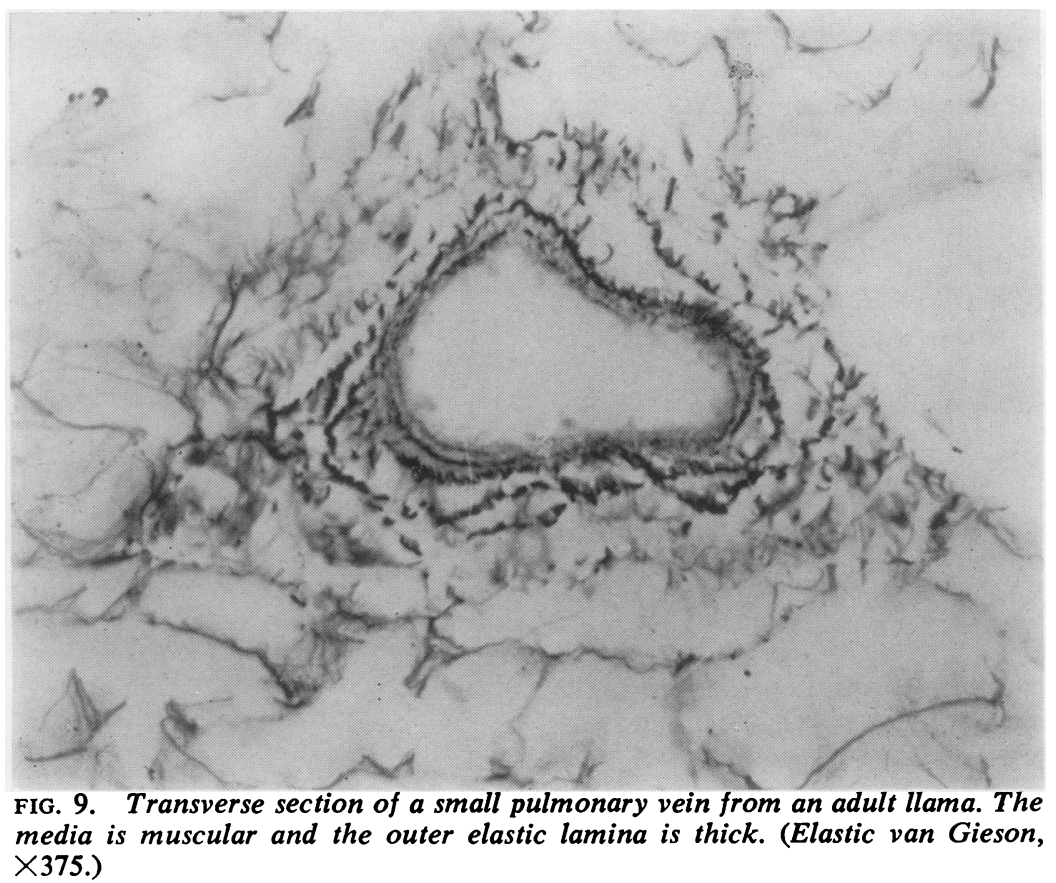


FIG. 10. Part of transverse section of an elastic pulmonary artery from a fetal llama. The thick internal elastic lamina is seen to the right and the fibrous adventitia to the left. Within the thick media are well-defined thick elastic laminae. (Elastic van Gieson, $\times 230$.)
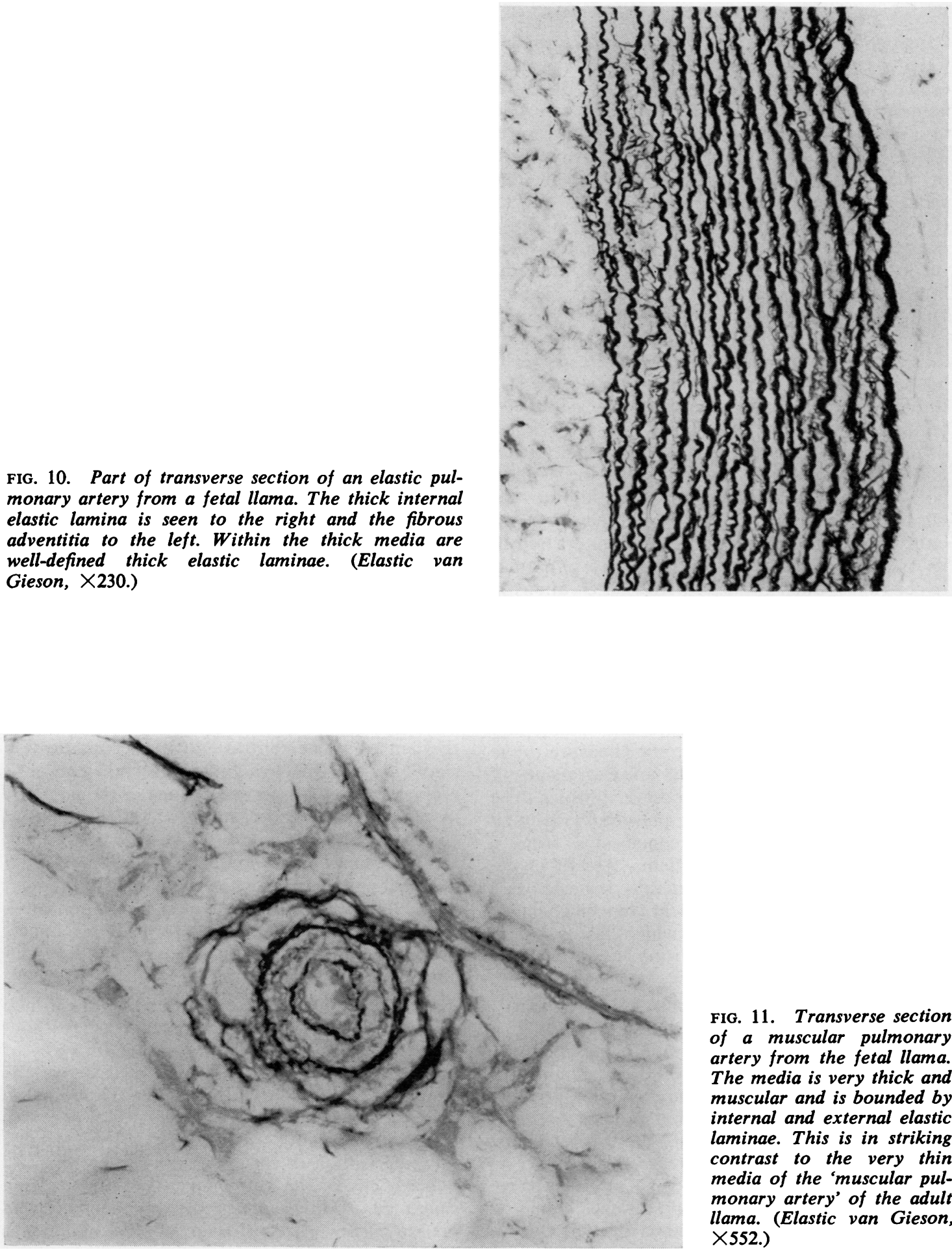

FIG. 11. Transverse section of a muscular pulmonary artery from the fetal llama. The media is very thick and muscular and is bounded by internal and external elastic laminae. This is in striking contrast to the very thin media of the 'muscular pulmonary artery' of the adult llama. (Elastic van Gieson, $\times 552$. 


\section{DISCUSSION}

Comparison of quantitative data on ventricular weights in the two adult llamas with values accepted as normal in man suggests that the pulmonary circulation in the llama is not subjected to a sustained rise in pulmonary arterial pressure. Thus the ratio of left to right ventricular weight in these two animals was 3.5 and 3.0 , while the range given as normal in man is 2.3 to 3.3 (Fulton et al., 1952). Similarly, the PT/A ratios in the two llamas were 0.64 and 0.57 , values which lie in the normal range of 0.4 to 0.7 for the human lung after the age of 2 years (Heath, DuShane, Wood, and Edwards, 1959). The percentage medial thickness of the small pulmonary arteries in the two adult llamas was respectively 3.8 and 4.9 and in our previous investigation of a third adult llama it was 3.6 (Heath et al., 1969). In the human lung a percentage medial thickness of less than 5 may be regarded as normal (Heath and Whitaker, 1955). Thus, although the llama is born into and exposed throughout life to the chronic hypoxia of high altitude, it does not show either muscularization of the terminal portion of its pulmonary arterial tree or right ventricular hypertrophy when compared with observations in man and other mammals. This suggests to us that the llama does not have a sustained significant pulmonary hypertension.

The llama has lived in the Andes for many centuries and it seems likely that the lack of structural change in its heart and pulmonary vasculature in the face of chronic exposure to the hypoxia of high altitude is an expression of evolutionary adaptation to these conditions. The data we have collected on the present two animals support our findings and conclusions from a previous study on a single llama (Heath et al., 1969). Such adaptation is generally regarded as a genetic, heritable, anatomical or biochemical modification of an organism which has enabled it to explore a particular environment to the best advantage.

Banchero et al. (1971) doubt this view partly on the grounds that in three young male sea-level llamas, aged 5, 7, and 14 months respectively, who were born and bred at St. Louis, Missouri the average resting mean pulmonary artery pressure rose from $14 \mathrm{mmHg}$ to $23 \mathrm{mmHg}$ after spending 10 weeks at an altitude of $3,420 \mathrm{~m}$ at Climax, Colorado. There was an increase of resistance to blood flow in these animals. We interpret these findings as indicating that in sea-level llamas at least, acute exposure to hypoxia may produce a mild pulmonary hypertension. However, we believe that our anatomical and histological findings show that in llamas born and living at high altitude chronic hypoxia does not induce significant chronic pulmonary hypertension with associated structural changes in the right ventricle, pulmonary trunk, and terminal portions of the pulmonary arterial tree such as occur in the Quechua Indian (Arias-Stella and Saldaña, 1963; Saldaña and Arias-Stella, 1963). Banchero and his associates (1971) also base their doubts on their observation of the pulmonary vasculature in one of their llamas who died from pulmonary thromboembolism. These authors do not provide quantitative data on the pulmonary arteries as their paper is physiological rather than anatomical in nature. Instead they illustrate a single pulmonary arteriole showing muscularization of its media and a single muscular pulmonary artery showing a very thick media. We find it difficult to reconcile these histological features with our own findings on one llama previously (Heath et al., 1969) or in the two adult llamas described here. The thinness of the media of the muscular pulmonary artery of the adult llama can be appreciated if it is compared with the thick small pulmonary arteries of the lung of the fetal llama $\stackrel{\square}{\square}$ (Figs 5 and 11). In the fetus the mean medial $\overrightarrow{\overrightarrow{0}}$ thickness is in the region of $20 \%$ (Table III) and $\frac{3}{3}$ this is explained by the physiological pulmonary hypertension which characterizes the fetus.

Adaptation to life at high altitude exhibited by the llama may be contrasted with acclimatization shown by the Quechua Indian. Acclimatization is a reversible, non-inherited change in the anatomy or physiology of an organism which enables it to survive in an alien environment. Changes in high altitude man which appear to aid acclimatization include hyperventilation, a decreased $\mathrm{A} / \mathrm{a}$ gradient said to be associated with dilated alveoli and capil- $\frac{D}{0}$ laries facilitating the area for gas exchange, polycythaemia, an increased myoglobin content, $N$ and so on.

However, not all the changes which are found in the Quechua Indian can be accepted without reservation as being due to acclimatization or indeed as desirable. Thus, as noted above, he $\frac{0}{\square}$ responds to the chronic hypoxia of mountain $\stackrel{\oplus}{\rightarrow}$ dwelling by chronic pulmonary hypertension with 0 associated right ventricular hypertrophy, muscularization of the pulmonary arterioles, and $\stackrel{\otimes}{\Phi}$ hypertrophy of the pulmonary trunk. It has been $\mathbb{\mathbb { D }}$ suggested that the elevated pulmonary arterial pressure may aid perfusion of the pulmonary 
capillary bed, facilitating gas exchange. However, all these changes can be induced in rats in a hypobaric chamber in the laboratory and will eventually terminate in death from congestive cardiac failure. They do not occur in the right ventricle or pulmonary circulation of the llama and it seems likely that this has favoured the survival of this species at high altitude.

It is of interest that, although the small pulmonary arteries of the llama are thin-walled, its pulmonary trunk is very muscular compared to that of man. Nevertheless its histology, extensibility, and chemical composition do not differ significantly from those of the pulmonary trunk of other high-altitude animals that we have examined previously (Heath, Harris, Castillo, and Arias-Stella, 1968). Chemically the content of elastin in the pulmonary trunk of the llama is similar to that found in man, although the amount of collagen is lower (Castillo et al., 1967). The ratio of elastin to collagen tends to increase with age in man so that the figures we found for a single llama are higher than one would expect from man at sea level but comparable to those found in persons living at high altitude who have an aortic pattern of elastic tissue in the media of the pulmonary trunk. In spite of its musculoelastic structure the extensibility of the tissue of the pulmonary trunk of the llama is greater than the average found in the first two decades of life in man (Heath et al., 1968). This is probably because extensibility is simply a direct function of time rather than a proportional function of the average longevity of the species.

Professors Harris and Heath acknowledge the receipt of a research grant from the Nuffield Foundation to undertake this study.

\section{REFERENCES}

Abraham, A. S., Kay, J. M., Cole, R. B., and Pincock, A. C. (1971). Haemodynamic and pathological study of the effect of chronic hypoxia and subsequent recovery of the heart and pulmonary vasculature of the rat. Cardiovascular Research, 5, 95.

Alexander, A. F. (1962). The bovine lung: normal vascular histology and vascular lesions in high mountain disease. Medicina Thoracalis (Basel), 19, 528.

Arias-Stella, J. and Saldaña, M. (1963). The terminal portion of the pulmonary arterial tree in people native to high altitudes. Circulation, 28, 915.

Banchero, N., Grover, R. F., and Will, J. A. (1971). High altitude-induced pulmonary arterial hypertension in the llama (Lama glama). American Journal of Physiology, 220, 422.

Brenner, O. (1935). Pathology of the vessels of the pulmonary circulation. Archives of Internal Medicine, 56, 211.

Castillo, Y., Krüger, H., Arias-Stella, J., Hurtado, A., Harris, P., and Heath, D. (1967). Histology, extensibility, and chemical composition of pulmonary trunk in persons living at sea-level and at high altitude in Peru. British Heart Journal, 29, 120.

Fulton, R. M., Hutchinson, E. C., and Jones, A. M. (1952). Ventricular weight in cardiac hypertrophy. British Heart Journal, 14, 413.

Heath, D., Castillo, Y., Arias-Stella, J., and Harris, P. (1969). The small pulmonary arteries of the llama and other domestic animals native to high altitudes. Cardiovascular Research, 3, 75.

, DuShane, J. W., Wood, E. H., and Edwards, J. E. (1959). The structure of the pulmonary trunk at different ages and in cases of pulmonary hypertension and pulmonary stenosis. Journal of Pathology and Bacteriology, 77, 443.

Harris, P., Castillo, Y., and Arias-Stella, J. (1968). Histology extensibility and chemical composition of the pulmonary trunk of dogs, sheep, cattle and llamas living at high altitude. Journal of Pathology and Bacteriology, 96, 161.

— and Whitaker, W. (1955). The pulmonary vessels in mitral stenosis. Journal of Pathology and Bacteriology, 70, 291.

Hecht, H. H., Lange, R. L., Carnes, W. H., Kuida, H., and Blake, J. T. (1959). Brisket disease. I. General aspects of pulmonary hypertensive heart disease in cattle. Transactions of the Association of American Physicians, 72, 157.

Saldaña, M. and Arias-Stella, J. (1963). Studies on the structure of the pulmonary trunk. III. The thickness of the media of the pulmonary trunk and ascending aorta in high altitude natives. Circulation, 27, 1101.

Requests for reprints to: Professor D. Heath, Department of Pathology, University of Liverpool, Liverpool L69 3BX. 